\title{
Acerca do debate metodológico na investigação feminista
}

\author{
Paula Silva \\ Paula B. Gomes \\ Amândio Graça \\ Paula Queirós
}

https://doi.org/10.5628/rpcd.05.03.358

\section{RESUMO}

Os feminismos associados à ciência e ao campo da investigação desencadearam uma nova dimensão de críticas em meados dos anos 70, do século passado, ao sugerirem a existência de enviesamentos androcêntricos no desenvolvimento da investigação científica. O saber identificava o universal com o masculino, e o feminino, quando contemplado, constituía o exemplo de resultados desviantes, reforçando a assunção do senso comum: inferioridade e subordinação do sexo feminino. São identificáveis fases na investigação feminista: a da 'visibilidade', com estudos só sobre mulheres; a da 'diferença', cujos estudos se debruçavam sobre a diferença de géneros; e a de 'relações de género', que se centra nas relações entre mulheres e homens. O debate acerca dos princípios da investigação feminista e das comple xas relações entre epistemologia, metodologias e métodos continua numa tentativa de clarificar uma questão central: o que significa fazer investigação feminista? Não se pretende nestas linhas de refle xão solucionar dilemas que são objecto, desde há alguns anos, de debates entre académicos - feministas e não feministas - e mesmo entre feministas, mas tornar públicos e objecto de refle xão os temas desses debates. Porque, estamos certos, promoverão uma visão mais crítica e refle xiva dos nossos próprios processos de investigação, enquadrem-se ou não na investigação feminista. Pretende-se, sim, com este artigo, dar visibilidade e sublinhar a pertinência da inclusão da investigação feminista na agenda das ciências do desporto.

Palavras-chave: investigação feminista, epistemologia, metodologias, ciências do desporto.

\author{
Universidade do Porto \\ Faculdade de Desporto \\ Portugal
}

\begin{abstract}
About methodological debate in the feminist research

Feminisms, related to the scientific and research community, fuelled a new dimension of criticisms in the middle 70's of the last century, by suggesting the existence of androcentric bias in the development of scientific research. Tacitly knowledge identified the universal with the masculine, and when contemplated the feminine constituted the example of deviated results, strengthening the common sensical assumption of the inferiority and subordination of female sex. There are identifiable phases in the feminist research: the "visibility" phase, with studies only on women; the "difference" phase, whose studies queried the differences of gender; and the "gender relations" phase, which focuses on relations between men and women. The debate about the principles of feminist research and the complex relations between epistemology, methodologies and methods, continues to evolve, attempting to clarify a central question: what does it mean to do feminist research? It is not intended in these lines to solve dilemmas that are, since a few years ago, object of debates between feminists and non feminists scholars, or even among feminists, but to make apparent the themes of those debates, and making them object of reflection once we are sure it will promote a more critical and reflexive vision of our own research processes, whether they fit or not in the feminist research. The very focus of this paper is to enhance the visibility and highlight the worth of including feminist research within sport studies agenda.
\end{abstract}

Key Words: feminist research, epistemology, methodologies, sport sciences. 
Quando iniciámos o percurso para este estudo fomos confrontados, logo à partida, com diversos caminhos que tivemos o cuidado de explorar per se. Ao calcorrear esses diversos caminhos ficámos conscientes que não existe algo como um feminismo, não existe um discurso único para este tema, bem como não pode ser visto como um tema exclusivo de mulheres.

Reconhecendo -se como importantes movimentos, políticos e sociais, os feminismos também contribuíram decisivamente para a emergência de novos temas e debates nas diversas áreas científicas, desenvolvendo novas epistemologias. A produção de conhecimento assente nestas novas premissas estendeu-se a diversos campos de estudo, com importantes repercussões na investigação do desporto e da educação física. No entanto, no nosso país são escassos os estudos ou ensaios de investigação feminista nas ciências do desporto. Pretende-se, assim, com este artigo, dar visibilidade a este campo teórico e sublinhar a pertinência da sua inclusão na agenda da investigação.

\section{OS FEMINISMOS E A CIÊNCIA}

'Feminismo' não é um conceito unitário, mas agrupamentos de ideias, múltiplas e diversificadas, bem como de acções. Parece consensual que não podemos definir o 'feminismo', podemos unicamente captar características comuns dos diferentes 'feminismos'. Qualquer tentativa de definir uma base comum a todos os feminismos pode começar pela afirmação de que os feminismos se interessam pela posição inferior da mulher na sociedade e pela sua discriminação. Além disso, podemos referir que todos os feminismos clamam por mudanças de ordem social, económica, política ou cultural, de modo a diminuir e eventualmente superar todas as formas de discriminação contra a mulher. No entanto, para além destas afinidades parece ser difícil de encontrar 'campos comuns' entre os diferentes feminismos, pelo que as ideias, história e práticas que os feminismos tendem a reivindicar como suas estão longe de uma unificação e, felizmente, sujeitas a um contínuo debate (12). O feminismo não é um movimento exclusivo de mulheres, mas em prol das mulheres, globalmente inserido num projecto único de dignificação da pessoa, envolvendo todos os membros da sociedade, pelo que se torna redutor o seu singular já que são múltiplos os caminhos de realização da mulher e do contributo do homem para a tornar possível (7). E se é verdade que as mulheres beneficiaram com algumas das mudanças na sociedade, apesar desses avanços, as discriminações mantêm-se e em alguns casos acentuam-se. "Deste modo, falar hoje de um pósfeminismo com uma base de acentuação centrada na "livre escolha" de cada mulher introduz uma lógica neoliberal que significa tornar anacrónicas as reivindicações das mulheres, num conte xto onde elas continuam actuais e necessárias" (36). As discriminações diferem consoante o conte xto social e histórico, apresentando -se, actualmente, mascaradas numa sociedade que apregoa mais do que pratica, que legisla mas não age, assumindo as mais diversas formas resguardadas por um ilusório direito de todas as mulheres à igualdade.

Para Lipovetsk y ${ }^{(24)}$, estamos em vias de um novo feminismo, "que reivindica o poder em igualdade com os homens, que procura reconciliar as mulheres com o prazer de vencer e com o espírito de competição, que as convida, desembaraçadas que estão das suas antigas inibições, a partir ao assalto da hierarquia. Após o feminismo vitimário, eis chegada a hora de um «feminismo do poder»" (24:258). Ou seja, defende-se que as mulheres devem abandonar o velho 'feminismo vitimário' que as coloca como vítimas inertes à espera de ajuda, em favor de um 'feminismo de poder' que as vê como poderosas agentes de mudança.

\section{ACERCA DOS FEMINISMOS}

Em meados dos anos 70 do século passado, os feminismos associados à ciência e ao campo da investigação desencadearam uma nova dimensão de críticas ao sugerir a existência de enviesamentos androcêntricos no desenvolvimento da investigação científica. O saber identificava o universal com o masculino, e o feminino, quando contemplado, constituía o exemplo de resultados desviantes, reforçando a assunção do senso comum de inferioridade e subordinação do sexo feminino.

Uma investigação que estude uma população de mulheres, ou um estudo cuja amostra seja composta exclusivamente por indivíduos do sexo feminino não é necessariamente um estudo que se enquadre na 
investigação feminista. Por outro lado, é possível que estudos desenvolvidos sem qualquer preocupação feminista apresentem resultados que perspectivam transformações no sentido de, por exemplo, uma melhoria na vida de um grupo de mulheres. Um caso paradigmático é o da obra de Simone de Beauvoir, O Segundo Sexo. Obra geralmente considerada como uma das mais significativas manifestações do moderno feminismo, embora, na altura da sua realização (1949), a sua autora não se considerasse uma feminista '. Claro que haverá poucas 'Simones', mas estudos que à partida não sejam estruturados como feministas, ou que como tal não se assumam, ao contribuírem para uma melhoria na vida das mulheres, ou para o seu melhor entendimento, serão estudos que indiscutivelmente se enquadram na investigação feminista.

Um dos grandes entraves ao desenvolvimento de estudos feministas reside na cadeia de reacções e associações pejorativas que o termo feminismo ainda provoca (1) (3) (6) (15) (30).

Outro reside na afirmação descabida de que hoje em dia já não faz sentido falar em feminismo. Não nos parece útil gastar tempo a debater tal afirmação, não nos merece qualquer comentário porque quem tal afirma ou vive numa sociedade virtual, ou pretende fazer (re)vigorar ideologias discriminatórias e sexistas perpetuando teorias e práticas androcêntricas.

Partilhamos em absoluto do desabafo de Carmo e Amâncio (6:11) : "Feminismo, palavra maldita. Um termo que suscita reacções indignadas, risos, ou o presunçoso comentário de que «isso já passou de moda»". Invariavelmente ao apelidarmos algo ou alguém de feminista desencadeamos alguma perple xidade associada a uma estereotipização do seu significado que leva, frequentemente, a uma intrínseca necessidade preconceituosa de objectar: "Eu não sou feminista, mas...". Esta é uma frase recorrente daquelas mulheres que se pretendem afastar de um estereótipo limitativo, de uma caricaturização do feminismo veiculada por fantasiadas histórias e por mitos. No entanto, expressa uma preocupação pela constatação da existência de alguns problemas, nomeadamente vivências e percepções de desigualdade social. Esta frequente atitude parece estar relacionada com o aparecimento de um movimento reactivo contra os feminismos: o backlash ${ }^{2}$. Mudanças políticas, a educação das gerações mais jovens ${ }^{3}$ e a designada interface família/carreira ${ }^{4}$ parecem ser aspectos relevantes no surgimento deste movimento (30).

O feminismo, que se tornou uma das mais importantes causas políticas e ideológicas das últimas décadas, pode tomar variadas formas, embora pareça ser comum a todas elas a tese de que a relação entre os sexos se caracteriza pela desigualdade ou opressão. Em geral, todas as formas de feminismo procuram identificar as causas dessa desigualdade e corrigi-la, sendo a questão de qual o(s) agente(s) que produz(em) e reproduz(em) essa desigualdade a fonte de muitas das diferenças ideológicas e políticas entre os feminismos.

É interessante notar que, embora o termo feminismo não tenha sido inicialmente usado pelas mulheres para se descreverem a si mesmas ou as suas acções ${ }^{5}$, o que hoje designamos de pensamento e acção feminista esteve presente bem antes do termo em si ter sido adoptado. Mesmo antes do aparecimento de todos os movimentos organizados para o direito ao voto, houve mulheres que escreveram acerca das desigualdades e injustiças da sua condição social, fazendo campanha para a mudança ${ }^{6}$.

A realidade que o feminismo procura mudar tem muitos nomes e variadas faces sendo entendida diversamente pelas diferentes teóricas feministas. Virtualmente todos(as) são consensuais de que a maioria das culturas actuais e passadas foram estruturadas dum modo que sistematicamente colocava, e coloca, em desvantagem as mulheres. Muitas(os) teóricas(os) feministas reconhecem outras hierarquias na ordem social além da de género: a de raça, classe social, orientação sexual, idade, etc. Portanto, a designada práxis ${ }^{7}$ feminista pode tomar muitas direcções e assumir variados interesses. Enquanto que a maioria das feministas partilha a visão de uma sociedade que injustamente privilegia determinados grupos em detrimentos de outros, os(as) teóricos(as) diferem na descrição das origens, mecanismos e formas de manifestação das relações de poder - relações de dominação -subordinação (5). Para Nogueira (30), são quatro as teorias feministas que continuam objecto de discussão e debate: a socialista, a liberal, a radical e a cultural. Mas outras teorias feministas devem ser consideradas: a psicoanalítica (25) (29) a pós-moderna (29) e a desenvolvida com uma perspectiva étnica e racial ${ }^{(25)}$. 
Para Tavares (35) podemos considerar no nosso país, fundamentalmente enquadradas como movimentos sociais e políticos, três correntes feministas: a radical, a socialista-marxista e a liberal. Enquanto que para o feminismo radical, a dominação masculina sobre as mulheres e o reconhecimento da existência do patriarcado anterior ao capitalismo estão na origem da subordinação feminina, para o liberal seria suficiente a existência da consagração da igualdade jurídica porque, desse modo, teriam uma mesma base de igualdade de oportunidades sendo o seu sucesso proporcional ao investimento realizado. A corrente socialistamarxista funda as suas concepções na luta de classes como motor da história, dando particular destaque à opressão de género, às tensões existentes entre o capitalismo e as relações de género.

Para as feministas radicais, o sexo e o género constituem um sistema de dominação dos homens sobre as mulheres através do controlo da sexualidade e da sua capacidade reprodutiva. Entendem que este sistema é deliberado, não acidental, e que penetra outras instituições sociais, a comunicação social, a religião, mas particularmente a família, que justificam a subordinação das mulheres.

As feministas marxistas localizam o sistema de dominação masculina na divisão genderizada do trabalho. Argumentam no sentido da importância do género e da luta de classes e analisam os modos como duas estruturas paralelas, a economia (capitalismo) e a família (patriarcado), estruturam as vidas das mulheres. Já para as feministas psicanalíticas o género é uma ideia de diferença que emerge das relações familiares. Centram-se na sexualidade como uma poderosa força cultural e ideológica que oprime as mulheres porque está inscrita nos corpos e no inconsciente.

Escritores(as) feministas com uma perspectiva étnica e racial ${ }^{8}$ consideram incorrecto construir uma investigação e teoria feminista assente numa oposição binária de mulheres e homens, quando a raça e as classes sociais produzem múltiplas categorias de mulheres e homens, base de um sistema hierárquico em muitas sociedades. Também as feministas culturais desafiaram o conceito das categorias de género como duais e opostas, apresentando a sexualidade e o género como categorias mutáveis e fluídas. Críticas quanto a uma política unicamente baseada no esta- tuto de subordinação das mulheres, apresentam uma visão mais subversiva que abala a solidez de uma ordem social construída nos conceitos de dois sexos e dois géneros (25).

Não nos parece possível analisar, de forma simples e consensual, o feminismo pós-moderno. O pósmodernismo caracteriza-se pelo constante questionamento da razão e da ordem, possibilitando novos entendimentos e relações com o mundo alterando muitas noções tidas como universais, como sejam as noções de 'feminino' e de 'masculino' (8). Mas se para feministas como Jane Flax, Linda Nicholson e Donna Haraway, o pós-modernismo indicia uma importante mudança, para outras, como Susan Bordo, Nancy Hartsock e Sandra Harding, é gerador de algum desconforto. Ao suspeitar do generalizável e de qualquer teoria coerente o pós-modernismo pode adoptar essa atitude em relação ao próprio feminismo (4) e colocar em questão a própria categoria de género enquanto categoria universal (4) (19). Subjacente a estas desconfianças está a ideia de que o sujeito pósmoderno, fragmentado e instável, não é mais que um renovado arquétipo do sujeito masculino típico do iluminismo. Enquanto importantes movimentos políticos e culturais das últimas décadas, os feminismos e o pós-modernismo parecem ter mantido sempre relações algo conflituosas. Mas o feminismo pósmoderno possibilita conjugar as forças dos dois movimentos, eliminando -lhes as fraquezas: uma refle xão pós-moderna da teoria feminista revelará nesta indícios de essencialismo; uma refle xão feminista acerca do pós-modernismo mostrará sinais de androcentrismo e ingenuidade política ${ }^{(11)}$. A teoria feminista pós-moderna implica o afastamento de noções unitárias de mulher e de identidade de género feminina, e a adopção de concepções comple xas, plurais e em construção, de identidade social. O género é importante, tal como o é a idade, a etnicidade e a orientação sexual (17).

\section{AS EPISTEMOLOGIAS FEMINISTAS}

Investigar é uma das diversas maneiras de conhecer ou entender. O modo de olhar o mundo - paradigma - é composto por assunções filosóficas que guiam e direccionam o pensamento e a acção. Guba e Lincoln (14) identificam três questões que ajudam a definir paradigma: (1) a questão ontológica - qual é a natu- 
reza da realidade?, (2) a questão epistemológica qual é a natureza do conhecimento e qual a relação entre o investigador e o que há a conhecer?, e (3) a questão metodológica - como é que o investigador pretende obter o conhecimento desejado?

Epistemologia, metodologia e método são conceitos não estáticos, que estabelecem entre si fortes ligações, mas que fluem consoante o conhecimento. Duas epistemologias dominantes emergiram do fundacionalismo ${ }^{9}$ : o positivismo e, em sua oposição, o interpretativismo (16). A estas associa-se uma terceira, a epistemologia emancipatória, na qual se enquadra a feminista, que perspectiva uma relação interactiva entre investigador(a) e participantes e o conhecimento situado em termos históricos e sociais (28). Para Stanley (33), o feminismo não é simplesmente uma perspectiva, um modo de ver; nem tão pouco uma epistemologia, uma forma de conhecer, é também ontologia, ou seja, uma maneira de estar no mundo. "It is the experience of and acting against perceived oppression that gives rise to a distinctive feminist ontology; and it is the analytic exploration of the parameters of this in the research process that gives expression to a distinctive feminist epistemology" (33:14).

Quando investigadores(as) das áreas da biologia e das ciências sociais tentaram acrescentar os conceitos de mulher e género aos corpos de conhecimentos já existentes experimentaram uma frustração. Os esquemas conceptuais e as noções dominantes de objectividade, racionalidade e metodologia científica eram extremamente débeis e dissimuladores para serem capazes de identificar, e muito menos eliminar, assunções e crenças sexistas e androcêntricas. Conceitos de 'conhecimento' e 'mulheres' foram sendo construídos em oposição nas modernas sociedades ocidentais. Com vista ao desenvolvimento de novas teorias do conhecimento emergiram principal mente três tendências feministas, três epistemologias: o empiricismo feminista (feminist empiricism), as teorias do ponto de vista feminista (feminist standpoint) e o feminismo pós-moderno (feminist postmodernism) ${ }^{(18)}$.

A primeira, o empiricismo feminista, assume uma posição liberal quanto à pesquisa, tentando corrigir preconceitos de género na investigação. Recorre aos métodos tradicionais, com predominância (mas não exclusividade) dos métodos quantitativos (38).
Fundamenta-se na racionalidade e objectividade da ciência e, dessa forma, tenta debelar todas as formas e manifestações de atitudes sexistas na investigação. É uma réplica, como argumenta Harding (1991), aos preconceitos sexistas na investigação tradicional e a uma visão androcêntrica dominante nas ciências sociais. O empiricismo feminista desenvolveu-se em consonância com o feminismo liberal, e, tal como a teoria liberal feminista, visa a identificação e a eliminação de estereotipias, sexismos e discriminações em qualquer processo de investigação (32). Mas é alvo de críticas ao não questionar as bases da investigação cientifica, nem desafiar a própria 'natureza' do conhecimento (33).

Já para as teóricas do ponto de vista feminista (standpoint), uma renovação da ciência tem inevitavelmente que incluir as experiências específicas das mulheres. Perspectivadas por uma teoria feminista, as experiências das mulheres potenciarão o desenvolvimento de um conhecimento mais completo, menos distorcido ou enviesado, do que o conseguido pelas experiências dos homens. Muitas das vezes as experiências das mulheres são alienadas por não serem capazes de se enquadrarem num esquema conceptual dominante baseado unicamente nas experiências dos homens ${ }^{(18)}$. Mas se o ponto de partida e o foco da investigação feminista são as experiências das mulheres, então não deve ser considerado um 'ponto de vista' único e universal. Uma das principais críticas, particularmente das feministas radicais, a muita da teoria feminista é a sua tendência para a universalização de conceitos como 'mulheres' ou 'ponto de vista feminino'. É importante reconhecer que as mulheres são diferentes e não podem ser simplesmente assim categorizadas sem ter em consideração as relações que, como grupo, estabelecem com outros grupos como sejam: raça, idade, classe social, portadores de deficiência, etc. Então, em termos epistemológicos, temos que falar numa pluralidade de 'pontos de vista feministas' (32).

As epistemologias identificadas com o iluminismo 10 foram colocadas em dúvida por várias feministas associadas a movimentos gerados contra o iluminismo, e por feministas das correntes do pós-modernismo e do pós-estruturalismo 11 .

Estas teóricas feministas questionaram e confrontaram as bases teoréticas do empiricismo do ponto de 
vista feminista (standpoint), e desencadearam novas perspectivas epistemológicas feministas com estreitas relações com o pensamento pós-moderno.

O feminismo pós-moderno sugere a existência de variados pontos de vista feministas contraditórios e conflituosos, considerando impossível a noção unitária de verdade. A tradicional investigação em ciências sociais está associada aos valores e princípios que precisamente o pós-modernismo tenta transcender. Logo, a realidade é passível de ser obser vada, estudada e entendida pelo recurso às análises de texto e de discurso. Isto não significa que os estudos feministas saiam a perder com esta abordagem pósmoderna, bem pelo contrário. Ao apresentar assunções radicalmente diferentes das outras posições epistemológicas tem, potencialmente, diferentes coisas a oferecer (27). Entre os investigadores pósmodernos reconhece-se a inexistência de um 'modo correcto' na interpretação dos dados. É da responsabilidade do investigador(a) explorar as possíveis e diferentes interpretações (38).

Para Hall (16), as ciências humanas estão no período pós-positivista, marcado por uma emergência metodológica e epistemológica de que resulta um espectro das diferentes posições feministas quanto à epistemologia. Por vezes neste espectro, as discrepantes tonalidades debatem ideias contraditórias sobre quem sabe o quê, acerca de quem e de como legitimar esse conhecimento. "... there can be no 'right' or 'correct' feminist epistemology, and there can be no hegemony of one form of feminism over all others" (16:73). Esta tensão interna e relacional existente nas epistemologias feministas não será uma forma de impedir a afirmação de uma epistemologia (e sequente política) hegemónica no feminismo? Estes debates infindáveis no seio das teóricas(os) feministas não serão um modo de evitar que uma das correntes feministas se assuma como 'o discurso dominante'? Sem dúvida que sim ${ }^{(34)}$.

\section{A INVESTIGAÇÃO FEMINISTA}

São identificáveis diversas fases na investigação feminista: (1) a da 'visibilidade', com a eclosão de estudos sobre mulheres; (2) a da 'diferença', cujos estudos se debruçavam sobre o que diferenciava homens e mulheres; e (3) a de 'relações de género', que se centra nas relações entre mulheres e homens, os estudos de género.
Os objectivos de cada uma destas fases, pertinentes nos respectivos momentos históricos e contextos sociais e culturais, parece-nos não serem de desprezar nem excluir no actual momento e conte xto da investigação feminista no nosso país. Na verdade, estes temas quando abordados e discutidos na nossa sociedade, e em particular no meio académico, têm de enfrentar verdadeiros adamastores, avançando, pela persistência, numa velocidade lenta, inconstante, por vezes com desacelerações acentuadas, mas sempre progredindo. Para nós continua hoje a ser oportuno o desenvolvimento de estudos que contemplem os objectivos das diversas fases. Isto é, entendemos que no nosso país ainda é fundamental desenvolver estudos que dêem visibilidade às mulheres e aos papéis por elas desempenhados nos diversos âmbitos sociais, estudos que divulguem as diferenças entre homens e mulheres e notifiquem as discriminações que elas, mas também eles, estão sujeitos(as), e estudos que se centrem nas relações sociais entre homens e mulheres, ou melhor nas relações de género ${ }^{12}$.

Uma etapa essencial na investigação feminista foi as mulheres deixarem de ser objecto de investigação e passarem a ser reconhecidas como sujeitos históricos, políticos e epistemológicos. (31)

Mas o debate acerca dos princípios da investigação feminista e das comple xas relações entre epistemologia, metodologias e métodos continua numa tentativa de clarificar uma questão central: o que significa fazer investigação feminista?

A investigação feminista inscreve-se numa actividade mais ampla, a ciência, mas apresenta determinadas características que a distingue da investigação tradicional. A relação entre investigação feminista e a investigação científica tradicional toma a forma de um compromisso crítico que levou a pôr muitas vezes em causa, de forma radical, os saberes estabelecidos e mesmo os processos de produção de conhecimento. Uma primeira característica da investigação feminista apontada por Ollivier e Tremblay (31) é a sua dupla dimensão: por um lado ela representa um projecto social e político de transformação das relações sociais e, por outro, um projecto científico de elaboração de conhecimentos. Ou seja, visa conhecer mas fundamentalmente mudar as condições económicas, cultu- 
rais e sociais que legitimam e perpetuam a subordinação das mulheres nas diversas sociedades e em todas as suas dimensões. Outra característica deste tipo de investigação é que ela implica uma transformação no modo de olhar o mundo, ao exigir não só o reconhecimento das mulheres como sujeito histórico e social, mas, sobretudo, o reconhecimento das relações sociais de sexo como factor de divisão e de hierarquização da vida social. Isto significa, para Lorber ${ }^{(25)}$, o reconhecimento da instituição social género ${ }^{13}$, porque, como qualquer outra instituição social, o género apresenta características universais e variações cronológicas e transculturais que afectam as interacções sociais e a vida das pessoas de muitas formas. Por último, este tipo de investigação caracteriza-se por ser multidisciplinar e transdisciplinar, dado que a questão das relações de género atravessa os campos disciplinares tradicionais: um mesmo problema pode ser analisado à luz de instrumentos conceptuais e metodológicos de disciplinas muito diferentes.

A ciência deve ser perspectivada como uma actividade multiforme, crítica e especulativa e, neste sentido, podemos afirmar que não existe um modelo único de investigação feminista mas meios que, necessariamente, devem ser privilegiados. Este pressuposto em favor do pluralismo teórico e metodológico não é estranho a uma característica essencial da investigação feminista mais recente - o reconhecimento da diversidade entre as mulheres. Algo que a investigação desenvolvida pelos movimentos de mulheres tem imposto, é que a categoria social 'mulheres' mascara um conjunto de condições de vida muito diversificadas (31).

Não podemos falar acerca de 'mulheres e ciência' ou de 'mulheres e conhecimento' sem explorar os diferentes significados e práticas acumuladas na vida de alguém que é uma mulher numa singular intersecção histórica de raça, classe e cultura ${ }^{(18)}$.

São alguns os princípios que estão associados à investigação feminista (31):

(1) o feminismo é uma perspectiva, não um método de investigação. A investigação feminista coloca um novo olhar sobre os objectos de estudos inscritos nos campos disciplinares das ciências sociais e sobre os métodos aí experimentados. Às vezes, através desse olhar, emergem e desenvolvem-se inovadores métodos de investigação, sempre com o objectivo de provocar modificações sociais no sentido de uma melhoria da vida das mulheres e de uma relação mais igualitária entre investigadores(as) e participantes. Outro aspecto importante é a valorização das experiências e das vivências das mulheres constituindo -se como ponto de partida da investigação;

(2) a investigação feminista recorre a vários métodos de investigação. Tende para uma diversidade de métodos. Os feminismos privilegiam a diversidade de perspectivas e, como tal, sujeitam o objecto de estudo a múltiplos olhares, e não a um único, permitindo uma imagem mais completa e comple xa. Uma certa flexibilidade parece ser uma estratégia necessária para estudar a problemática geral deste tipo de investigação: as relações de género e as experiências de vida das mulheres. Se no mundo a investigar impera a heterogeneidade e não a homogeneidade, então não há uma maneira de fazer investigação feminista mas maneiras de a fazer;

(3) desenvolve um olhar crítico ao interior das disciplinas. Este olhar desencadeia movimentos de desconstrução e de reconstrução dos saberes das disciplinas, tentando debelar estereotipias, preconceitos sexistas e androcêntricos nos processos de produção de conhecimentos e nos métodos;

(4) é guiada pelas teorias feministas. Estas ao acrescentarem as perspectivas de género e de relações de poder entre homens e mulheres no âmbito das várias disciplinas científicas desencadeiam transformações importantes nos vários campos disciplinares. Por exemplo, ao estudar a estratificação social verificou-se que o conceito de "classe social» era insuficiente para ilustrar o domínio a que as mulheres eram sujeitas numa determinada sociedade;

(5) tende para a multidisciplinaridade. A investigação feminista ocasiona colaborações entre diferentes disciplinas que adoptam múltiplas formas e modelos. No entanto, dado os demasiados obstáculos com que se depara, a multidisciplinaridade é mais um ideal do que uma realidade; 
(6) preocupa-se com modificações sociais. Uma das grandes preocupações da investigação feminista é que esta contribua para a promoção de mudanças sociais, quer através da consciencialização de que as experiências de vida das mulheres (e também dos homens) são socializadas e politizadas, quer pela prática, ao desenvolver projectos de investigação acção e ao propor recomendações e planos de acção para os variados agentes de poder social e político, no sentido de uma melhoria na vida das mulheres;

(7) reconhece e considera a diversidade entre mulheres (ou pelo menos esforça-se por tal). Ao abrir-se a uma realidade que é a diversidade dentro do grupo mulheres, ou seja, ao reconhecer que não há só mulheres brancas, ocidentais, de classe média, heterosse xuais, sem deficiência, etc, a investigação feminista desenvolveu uma nova e importantíssima dinâmica no campo da investigação;

(8) solicita o comprometimento do(a) investigador(a). Desta forma convida o(a) investigador(a) a questionar uma objectividade resultante duma visão exterior, neutra e despersonalizada, e a ponderar uma valorização das suas próprias experiências no processo de investigação;

(9) convida também ao compromisso dos(as) participantes na investigação. Consoante uma apreciação do conte $\mathrm{x}$ to da investigação, e se assim for desejável, a investigação feminista tenta estabelecer meios de ligação, formas de aproximação dos(as) participantes ao tema e aos objectivos da investigação;

(10) favorece o compromisso do público leitor. Este princípio decorre de um outro: a investigação feminista tenta promover modificações de ordem social. Como já referido, esse investimento na mudança implica um trabalho de consciencialização e de acção junto de todos(as) que se movem na área do estudo e da investigação, mas também junto de um público mais vasto. Se o que se pretende são mudanças sociais então os estudos e práticas que as legitimam não podem ficar fechados em espaços académicos ou de restrito acesso, nem podem deixar de reflectir os impactos e as opiniões de todos(as) os que deles tiveram conhecimento.

\section{UMA METODOLOGIA FEMINISTA?}

Epistemologia e metodologia devem ser equacionadas em conjunto e não como entidades dissociáveis. Esta afirmação, que não questionamos, conduz-nos à tentativa de caracterizar a investigação feminista em termos metodológicos. Isto é, para que determinado estudo se afigure como um 'verdadeiro' estudo feminista que metodologias deverá adoptar? Não parece que esta questão deva centrar as preocupações de quem pretende desenvolver investigação feminista, mas inevitavelmente surge no decurso de qualquer processo de investigação. Uma preocupação exagerada na determinação de uma metodologia específica desfoca o que é realmente importante e pertinente na investigação feminista.

Quando falamos de metodologias e feminismos pretendemos mais apontar aspectos que deverão ser sempre objecto de consideração em qualquer estudo feminista do que propriamente delinear metodologias ideais para o seu desenvolvimento. No entanto, foram as feministas que colocaram em causa muitas das assunções ditas 'inabaláveis' em qualquer processo de investigação e que alertaram para a incapacidade de certos princípios metodológicos responderem aos problemas que elas pretendiam estudar. Uma das preocupações em qualquer processo de investigação parece ser a extrema relevância na produção de resultados objectivos, alcançáveis através de processos que primam por perspectivas desapaixonadas e despersonalizadas do(a) investigador(a). Para uma real compreensão das experiências e vidas das mulheres é impossível seguir esta premissa. Uma desresponsabilização do(a) investigador(a) enquanto elemento inter ventivo no processo de investigação, ou a tentativa de omissão das suas características pessoais impressas por experiências, crenças e histórias de vida, unicamente cria uma ilusória noção de objectividade. Em vez de abdicarem da posição de sujeitos no processo de investigação com preocupações éticas e políticas, o(a) investigador(a) deve situar-se de uma forma refle xiva nesse processo.

Sugere-se que só minimizando o diferencial de poder entre quem estuda e quem (ou o que) é estudado será possível captar sentimentos, subjectividades e experiências da vida das mulheres. Foram várias as estratégias para diluir esta hierarquia entre investigador(a) e investigado(a): entrevistas não estrutura- 
das, histórias de vida, partilha de experiências durante as entrevistas e entrevistas menos formais. Mas as diferenças são fundamentalmente expressas em termos de factores como a idade, a classe social, a raça, aspectos culturais, etc. Qualquer investigação feminista precisa de ser sensível a este diferencial de poder entre mulheres e à forma como ele interfere no processo de investigação (32).

$\mathrm{O}$ (a) investigador(a) tem uma biografia pessoal arraigada numa determinada perspectiva de classe, género, raça, cultura e etnicidade. A posição multicultural e genderizada do(a) investigador(a) leva-o(a) a abordar o mundo com um conjunto de ideias, baseado numa determinada organização social (teoria, ontologia) que especifica num grupo de questões (epistemologia) que examina de forma específica (metodologias e métodos). Ou seja, o(a) investigador(a) recolhe material empírico relacionado com a questão que pretende estudar, analisa- o e escreve acerca dos resultados a que chegou. Todo e qualquer investigador(a) trabalha a partir de uma comunidade interpretativa distinta que configura, de uma determinada forma, as componentes multicultural e genderizada do acto de investigação (10).

Ficamos persuadidos que uma plena objectividade acaba por ser inatingível, salvo na imaginação daqueles que acreditam que o conhecer (knowing) pode ser separado de quem o produz (knower) ${ }^{(23)}$. Os processos de produção de conhecimentos não se assemelham a uma conquista impessoal de uma objectividade abstracta e neutra. Devem sempre ser vistos como processos enraizados em actos pessoais de integração tácita.

A validade sempre foi um conceito central na metodologia e em particular na área das ciências sociais, no sentido de perceber em que medida um estudo investiga o fenómeno que realmente pretende investigar .

A noção da modernidade de conhecimento como espelho da realidade foi substituída por um entendimento pós-moderno do conhecimento enquanto construção social. Numa concepção pós-moderna o entendimento do conhecimento como mapa de uma realidade objectiva, e a validade, enquanto correlação entre a realidade e o traçado do mapa, são substituídos por uma perspectiva da realidade como construção social e linguística onde o conhecimento é vali- dado pela prática. O conhecimento não se refere aos processos de interacção com uma realidade desumanizada, mas implica comunicação entre pessoas.

Assim, a deslocação do conhecimento enquanto fiel retrato da realidade para um conhecimento que se constrói envolve uma mudança de ênfase na observação para a conversação e interacção.

A validade decorre da qualidade na arte de investigar, o que inclui processos contínuos de verificação, questionamento e interpretação teórica dos resultados. Nesta abordagem da validade, a verificação no final de todo o processo é substituída por um controlo da qualidade durante todas as fases da produção de conhecimento (22).

O como e o quê estão indissociavelmente relacionados, e a natureza e forma do quê será o produto do como na investigação ${ }^{(33)}$. O que aqui se pretende evidenciar é que no âmbito do conjunto de preocupações metodológicas e epistemológicas de qualquer investigação, o método não pode ser visto como um assunto de menor importância ou significado. A par das importantes questões teóricas a definir, não devemos descurar a importância crítica dos processos utilizados para justificar e avalizar.

Mas mesmo sabendo que a investigação feminista privilegia a investigação de natureza qualitativa, não pode de todo desprezar a utilização de métodos quantitativos como instrumentos eficazes no alcance dos objectivos a que se propõe (embora cientes que muitas feministas assim não o pensam). A nossa preocupação não deve residir no método em si, mas antes no modo como esse método vai ser utilizado. Jayaratne \& Stewart (21) apresentam um conjunto de estratégias úteis para a implementação de uma perspectiva feminista, numa investigação em ciências sociais, no que respeita ao método a aplicar: (1) seleccionar um tópico de investigação que potencialmente contribua para uma melhoria da vida das mulheres; (2) propor métodos que sejam adequados ao que se pretende estudar; (3) sempre que possível utilizar no mesmo estudo métodos qualitativos e quantitativos; (4) levar a cabo múltiplas interpretações dos dados, consistentes com os resultados que possam implicar mudanças nas vidas das mulheres; e (5) atender sempre a uma análise política dos resultados (38). 


\section{A INSCRIÇÃO NA AGENDA DAS CIÊNCIAS DO DESPORTO}

Em Portugal, os estudos de género só a partir da década de 80 suscitaram o interesse de investigadores(as) ${ }^{14}$. Nos anos 90 o debate teórico acerca das questões de género começa a estar presente em trabalhos académicos em áreas científicas como a psicologia social (Lígia Amâncio e Conceição

Nogueira), a sociologia da educação (Helena Araújo) e a da família (Anália Torres e Elza Pais), a geografia humana (Isabel André), e a antropologia (Miguel Vale de Almeida e Teresa Joaquim). É um período em que se assiste a um significativo aumento da investigação neste domínio (37), embora, no nosso entender, com uma preocupante ausência de estudos no âmbito do desporto e da educação física. Em 2000, as refle xões sobre o género alargaram-se à filosofia (Maria Luísa Ferreira) e à psicologia (Lígia Amâncio e Conceição Nogueira) com uma interpelação das práticas disciplinares (2).

Embora existam algumas publicações periódicas nacionais relevantes e de qualidade, de importância crucial para o desenvolvimento de estudos no domínio da investigação feminista ${ }^{15}$, é difícil definir de modo inequívoco as correntes que sustentam o pensamento e a investigação feminista em Portugal. Esta situação pode dever -se ao facto de o feminismo da primeira vaga ter sido entre nós muito tardio se comparado com outros países, e ter esbatido a sua identidade na luta contra a ditadura (6). Deste modo, é escassa a investigação no domínio do género, e especificamente nas questões da igualdade de género em educação. A produção teórica já existente não consegue impor uma dinâmica de influência epistemológica na comunidade científica, a não ser de forma pontual e circunstancial (20). E se a investigação feminista se apresenta como um campo recente no nosso país, no domínio do desporto e da educação física encontra-se ainda numa fase de sensibilização para a importância do campo epistemológico feminista nos estudos naquele domínio, ou, no dizer de Anne Cova (9), numa "fase de acumulação" 16. Além fronteiras, podemos verificar que os estudos em desporto assentes em teorias feministas emergem com maior significado na década de 80 , dividindo-se entre os estudos que seguem uma perspectiva liberal e os estudos das perspectivas radical e socialista-marxista. Messner e Sabo (29) alertam para as visões algo inconciliáveis entre as correntes liberal e radical, numa não pacifica coexistência, embora se possa perspectivar, no futuro, uma 'radicalização' do feminismo liberal. As liberais, enquanto agentes de mudança na escola, procuraram que raparigas e mulheres tivessem mais oportunidades de praticar desporto ${ }^{17}$. Já as feministas radicais, tal como as socialistas-marxistas, desenvolveram teorias e análises históricas acerca dos valores e da estrutura genderizada do mundo do desporto.

Urge, no conte xto nacional dos estudos do desporto e da educação física, alertar para as implicações de natureza científica e de inter venção social e política da investigação feminista. A dupla marginalidade a que foi sujeito o tema das mulheres no desporto ${ }^{18}$ sustenta, ainda, a resistência que parece ocorrer sempre que queremos falar de mulheres e feminismos no âmbito do desporto e de desporto no âmbito dos feminismos. Se o desporto parece esquecer a genderização que o estrutura, o feminismo omite a importância social e cultural do desporto. O anátema das mulheres no desporto alicerçou-se em determinismos biológicos, e as questões da sexualidade emergiam sempre que se ousava desafiar uma visão hegemónica masculina.

Desta forma, os dilemas expressos nestas linhas sugerem mais estudos e espaços de debate, no intuito de apelar a uma visão mais crítica e refle xiva em qualquer processo de investigação. Embora pareça ser consensual que não se possa elencar as metodologias mais correctas em processos de investigação feminista no âmbito da educação física e do desporto, entendemos pertinente apontar três aspectos cruciais para o desenvolvimento deste campo de investigação (32) a nível nacional:

- é fundamental que toda a investigação na área da educação física e do desporto adopte, pelo menos, uma perspectiva empiricista feminista no sentido de remover todo e qualquer sinal da presença de ideias, atitudes e comportamentos preconceituosos ou discriminatórios do processo de investigação.

Essencialmente devem ser investigações não sexistas e que contemplem as opiniões, as experiências e os entendimentos das raparigas e mulheres, não só na fase da selecção dos problemas a estudar, mas também no desenvolvimento do próprio processo de investigação; 
- a questão das relações de género deve ser central em mais projectos de investigação. Nas publicações nacionais na área da educação física e do desporto este tema, com raríssimas excepções 19 não é tema. A investigação feminista, como já foi referido, tem também um papel político, e na educação física e no desporto o objectivo deve ser o de contribuir com expressivos resultados e conhecimentos que permitam não só questionar, mas também alterar políticas e práticas no âmbito da educação no e pelo desporto; - embora a investigação feminista seja para as mulheres, não significa que a tal se limite. Estudos acerca das experiências de rapazes e homens na educação física e no desporto são vitais para uma melhor compreensão de como as actividades físicas e desportivas reforçam (ou não) ideologias de masculinidades e de uma masculinidade hegemónica, e quais os seus entendimentos acerca das relações de género enquanto relações de poder.

Para além do exposto, haveria ainda a considerar que na investigação feminista é a práxis que induz a uma relação entre teoria e prática dado que, conforme Hall (16) admite, existe um hiato entre o que se passa dentro do meio académico e fora dele: "Praxis, therefore, acknowledges that what goes on academe, at least as far as feminism is concerned, should be directed at producing the kind of useful knowledge wanted and needed by those outside academe who are working for social change" (16:78).

CORRESPONDÊNCIA

Paula Silva

Faculdade de Desporto

Universidade do Porto

Rua Dr. Plácido Costa, 91 4200-450 Porto

Portugal

psilva@fcdef.up.pt 


\section{NOTAS}

${ }^{20}$ Só nos anos 70 do século passado é que Simone de Beauvoir se identifica com os movimentos feministas e se envolve em campanhas para os direitos da contracepção e do aborto (26). ${ }^{2}$ Identificam-se três vagas no movimento feminista: $1^{\text {a }}$ - com início no meio do século XIX, 2a - época desde os anos 60 até meados dos anos 80, $3^{\text {a }}$ - actual, caracterizada por fenómenos como o backlash que é um movimento contra o feminismo.

3 "As jovens deparam-se com um discurso legal e formal de igualdade associado a uma ridicularização dos movimentos feministas" (30:143).

${ }^{4}$ Para Davidson e Cooper (1982) trata-se da compatibilização de múltiplos papéis e exigências por parte das mulheres, que têm uma carreira e continuam a ser as responsáveis pela gestão doméstica (30).

${ }^{5} \mathrm{Na}$ terminologia médica feminismo foi usado para expressar a feminização do homem, e em termos políticos foi inicialmente usado para descrever a virilização da mulher. Esta confusão de género argumenta-se que ainda está presente de forma modificada nas sociedades de hoje, onde as feministas são por vezes percebidas como desafiando as naturais diferenças entre homens e mulheres (12).

${ }^{6}$ Mary Wollstonecraft escreveu em 1872 A Vindication of the Rights of Woman, na qual exigia a independência económica para as mulheres, o respeito pela igualdade, podendo -se considerar este livro, pelo seu conteúdo, como o primeiro livro feminista (30).

7 Práxis é um processo dialéctico de acção e refle xão motivado por um compromisso e por um empenho na mudança. "We research; we theorize; we act; we reflect. And the cycle is perpetual, without beginning or end; every phase of the cycle is only a matter of emphasis rather than a difference in kind" (5:413).

${ }^{8}$ Como bell hooks e Patricia Collins (25)

9 Ao reflectir acerca das opções quanto à estrutura na construção de teorias epistemológicas surge o que filósofos denominaram como fundacionalismo clássico que seria uma estrutura que estabelecia determinados requisitos na definição do que seria considerado conhecimento: restringe o conhecimento verdadeiro à designada crença verdadeira justificada, propondo uma estrutura através da qual as crenças eram justificadas tornando -se em conhecimento (13).

10 "Movimento intelectual europeu, também conhecido como «Luzes», que atingiu o seu auge no século XVIII. Os pensadores iluministas acreditavam no progresso social e nas capacidades libertadoras do conhecimento racional e científico. Eram frequentemente críticos da sociedade existente e manifestavam-se hostis à religião, que consideravam manter a mente humana aprisionada pela superstição"

http://www.universal.pt/scripts/hlp/hlp.exe/artigo?cod =6_276

11 Feministas como Donna Haraway, Lucy Irigaray e Jane Flax, ou Joan Scott e Judith Butler.

12 Embora não discordando da terminologia, mais usual nas correntes francesas, de relação sociais entre sexos, adoptámos uma terminologia associada ao termo gender-género.

13 “As is true of other institutions, gender's history can be traced, its structure examined, and its changing effects researched" (25:1).

14 Amâncio (2003) refere uma combinação de factores que terão contribuído para que a investigação neste domínio, desde 1974 até à década de 80 , tenha permanecido num estado de latência: o facto de as organizações de mulheres que foram surgindo nos anos 70 terem permanecido praticamente invisíveis e sujeitas a diversas contradições; o baixo nível de instrução, e particularmente das mulheres, ao longo do século XX; e o facto das ciências sociais terem um desenvolvimento recente no nosso país, o que impediu a difusão de instrumentos conceptuais e analíticos para o debate e a refle xão destas questões. ${ }^{15}$ Caso das revistas ex aquo da Associação Portuguesa de Estudos sobre as Mulheres e Faces de Eva, revista de estudos sobre a mulher.

16 Esta fase caracteriza-se por pesquisas empíricas de valor desigual (9)

17 Parecem ser algumas as limitações dos princípios de acção das feministas liberais uma vez que um aumento da participação das mulheres nas diversas áreas do mundo do desporto não significa necessariamente um passo em prol da igualdade e do empoderamento (empowerment) social.

18 Raramente as feministas prestaram atenção aos corpos das desportistas, nem tampouco realçaram a importância da prática desportiva, bem como desdenharam as potencialidades de empoderamento através da actividade física e desportiva nas suas políticas (16)

19 Exemplos de publicações nacionais no âmbito da investigação feminista: Equidade na Educação. Educação Física e Desporto na Escola (2000) Botelho Gomes P, Silva P, Queirós P; Mulheres e Desporto ex æquo, 4 (2001); Uma Vida pelo Desenvolvimento da Educação Física Feminina em Portugal: Ingrid Ryberg de Figueiredo (2002) Manuela Hasse (org.); «Sportwoman». A construção dos corpos desportivos femininos na imprensa desportiva portuguesa da década de 20 (2003) Cruz, I. Dissertação de Mestrado em Estudos sobre as Mulheres. Universidade Aberta. 


\section{REFERÊNCIAS BIBLIOGRÁFICAS}

1. Amâncio L (2002). O Género na Psicologia Social em Portugal. ex-aequo 6: 55-76.

2. Amâncio L (2003). O género no discurso das ciências sociais. Análise Social 168: 687-714.

3. Aronson P (2003). Feminist or "Postfeminists"? Young Women's Attitudes toward Feminism and Gender Relations. Gender \& Society 17(6): 903-922.

4. Bordo S (1990). Feminism, Postmodernism, and Gender Scepticism. In Nicholson LJ (Ed.). Feminism/Postmodernism. New York and London: Routledge, 133-154.

5. Bredemeier BL (2001). Feminist Praxis in Sport Psychology Research. The Sport_Psychologist 15: 412-418.

6. Carmo I, Amâncio L (2004). Vozes Insubmissas. A história das mulheres e dos homens que lutaram pela igualdade dos sexos quando era crime fazê-lo. Lisboa: Publicações Dom Quixote.

7. Castro Z (2003). Nota de Abertura. Faces de Eva 9:5-6.

8. Collin F (1991). Diferença e diferendo. A questão das mulheres na filosofia. In Duby G, Perrot M (Eds.). História das Mulheres. O século XX. Porto: Edições Afrontamento, 315-349.

9. Cova A (1998). L'enseignement de l'Histoire des Femmes dans la Péninsule Ibérique In Sohn AM, Thélamon F (org.). L'Histoire Sans les Femmes est-elle possible? Rouen : Perrin, 313-323.

10. Denzin N, Lincoln Y (2000). Introduction: The Discipline and Practice of Qualitative Research. In: Denzin NK, Lincoln YS (eds.). Handbook of Qualitative Research. Thousand Oaks CA: Sage Publications, 1-28.

11. Fraser N, Nicholson L (1990). Social Criticism without Philosophy: An Encounter between Feminism and Postmodernism. In Nicholson LJ (Ed.). Feminism/Postmodernism. New York and London: Routledge, 19-38.

12. Freedman J (2001). Feminism. Buckingham: Open University Press.

13. Gomes D (2000). A Suposta Morte da Epistemologia e o Colapso do Fundacionalismo Clássico. [on-line]: www .mack enzie.com.br/teologia/fides/vol05/num02/Davi. pdf

14. Guba E, Lincoln Y (1994). Competing paradigms in qualitative research. In: Denzin NK, Lincoln YS (eds.). Handbook of Qualitative Research. Thousand Oaks, CA: Sage Publications, 105-117.

15. Hall E, Rodriguez M (2003). The Myth of PostF eminism. Gender \& Society 17: 878-902.

16. Hall MA (1996). The "Doing" of Feminist Research. In: Hall MA (ed.). Feminism and Sporting Bodies. Champaign Il: Human Kinetics, 69-87.

17. Haraway D (1990). A Manifesto for Cyborgs: Science, technology, and Socialist Feminism in the 1980s. In Nicholson LJ (Ed.). Feminism/Postmodernism. New York and London: Routledge, 190-233.

18. Harding S (1991). Whose Science? Whose Knowledge? Thinking from Women's Lives. New York: Cornell University Press.

19. Hartsock N (1990). Foucault on Power: A Theor y for Women? In Nicholson LJ (Ed.). Feminism/Postmodernism. New York and London: Routledge, 157-175.

20. Henriques F, Pinto T (2002). Educação e Género. Dos anos 70 ao final do século XX: subsídios para a compreensão da situação. ex aequo 6: 11-54.

21. Jayaratne T, Stewart A (1991). Quantitative e Qualitative methods in the social sciences: Current feminist issues and practical strategies. In: Fonow MM, Cook JA (eds). Beyond methodology: Feminist scholarship as lived research. Bloomington: Indiana University Press, 85-106.

22. Kvale S (1995). The Social Construction of Validity. Qualitative Inquiry 1: 19-40.

23. Lincoln Y, Guba E (2000). Paradigmatic Controversies, Contradictions, and Emerging Confluences. In: Denzin NK, Lincoln YS (eds.). Handbook of Qualitative Research Thousand Oaks CA: Sage Publications, 163-188.

24. Lipovetsk y G (1997). A Terceira Mulher. Permanência e Revolução no Feminino. Lisboa: Instituto Piaget.

25. Lorber J (1994). Paradoxes of Gender. New Haven and London: Yale University Press.

26. Macey D (2000). The Penguin Dictionary of Critical Theory. England: Penguin Books.

27. Maynard M (1994). Methods, Practice and Epistemology: The Debate About Feminism and Research. In: Maynard M, Purvis J (eds.). Researching Women's Lives From a Feminist Perspective. London: Taylor \& Francis Ltd, 10-26.

28. Mertens D (1998). Research Methods in Education and Psychology. Integrating Diversity with Quantitative $\mathcal{E}$ Qualitative Approaches. Thousand Oaks CA: Sage Publications.

29. Messner M, Sabo D (1990). Introduction: Toward a critical Feminist Reappraisal of Sport, Men, and the Gender Order. In: Messner MA, Sabo DF (eds.). Sport, Men, and the Gender Order. Champaign, Il: Human Kinetics Books, 1-16.

30. Nogueira C (2001). Um Novo Olhar sobre as Relações Sociais de Género. Feminismo e Perspectivas Críticas na Psicologia Social. Braga: Fundação Calouste Gulbenkian/F undação para a Ciência e a Tecnologia.

31. Ollivier M, Tremblay M (2000). Questionnements féministes et méthodologie de la recherche. Paris: Collection Outils de Recherche Harmattan.

32. Scraton S, Flintoff A (1992). Feminist Research and Physical Education. In: Spark es AC (ed.). Research in Physical Education and Sport. London: Falmer Press, 167187.

33. Stanley L (1990). Feminist praxis and the academic mode of production: an editorial introduction. In: Stanley $\mathrm{L}$ (ed.). Feminist praxis: research theory and epistemology in feminist sociology. London: Routledge, 3-15.

34. Stanley L, Wise S (1990). Method. Methodology and epistemology in feminist research process. In: Stanley L (ed.). Feminist praxis: research theory and epistemology in feminist sociology. London: Routledge, 20-60.

35. Tavares M (2000). Movimento de Mulheres em Portugal. Décadas de 70 e 80. Lisboa: Livros Horizonte.

36. Tavares $\mathrm{M}(\mathrm{s} / \mathrm{d})$. História e Universos Femininos. Os Feminismos. [on-line]: www .aph.pt/uf/uf_0204.html

37. Vicente A (1998). As Mulheres em Portugal na Transição do Milénio. Valores - Vivências - Poderes nas Relações Sociais entre os Dois Sexos. Lisboa: Multinova.

38. Whaley D (2001). Feminist Methods and Methodologies in Sport and Exercise Psychology: Issues of Identity and Difference. The Sport Psychologist 15: 419-430. 